\title{
From Editors of Special Issue
}

DOI: $10.1134 / \mathrm{S} 1023193511100168$

The electrochemistry of organic compounds (ECOC) has traveled a long way from the Kolbe synthesis and reached the new frontiers in the beginning of the XXI century. In line with the modern trends are the studies on electrochemistry of fullerenes, electrochemistry of nanosized or supramolecular systems, studies associated with the development of methods of electrosynthesis including the electrosynthesis in ionic liquids, the multicomponent and tandem electrolsyntheses, and several other directions.

New aspects of ECOC have emerged that are directed on the immediate or future practical use of the results of studies, particularly, those associated with the advances in chemo- and biosensors, the simulation of operation of metal enzyme active centers, the development of systems and "molecular machines" (including nanosized) with redox-switchable properties, etc.

Many of these problems are reflected in the present issue of Journal Elektrokhimiya. Since 1966, this is the 13th collection (of materials delivered in ECOC conferences) which mainly reflects the work of the 17 th ECOC conference held on September 2010 on the basis of the Tambov State Technical University (TSTU).

In this conference, more than 100 reports were made by experienced specialists and also by young scientists and post graduates from the research and educational institutes of Russia, Ukraine, Belarus and Kazakhstan. This reflects the definite trend for the retention of contacts between the research centers that work in the ECOC fields of the former USSR republics, now independent states.

For some participants, this conference became the first opportunity to share their results with the scientific community. The authors of the best reports deliv- ered in the Session of Young Scientists were marked by the Organizing Committee.

In addition to traditional studies in the fields of functionalization and electrosynthesis of organic substances, including those using mediator systems, the lectures on the mechanisms of electrode reactions and mechanisms of transformations of electrochemically generated reactive species were presented. Some reports concerned the problems of the development of electrochemistry of metal complexes and the new aspects in electropolymerization. Finally, the distinguishing feature of the 17th ECOC Conference was the increased interest in the studies in the field of electrochemistry of nanostructured electrodes and conducting polymer nanocomposites and also the appearance of new studies on the tandem electrosynthesis.

For a number of reasons, several studies delivered at the conference some of which were already published in other journals did not enter the present issue. These are the studies on the multicomponent electrosynthesis (Elinson, M.N., Merkulova, V.M., Ilovaisky, A.I., Demchuk, D.V., Belyakov, P.F., and Nikishin, G.I., Molecular Diversity, 2010, vol. 14, p. 833), the electrosynthesis using a nickel-hydroxide electrode (Lyalin, B.V. and Petrosyan, V.A., Elektrokhimiya, 2010, vol. 46, p. 1283), the development of reactions of anodic substitution (Petrosyan, VA., Mendeleev Commun., 2011, vol. 21, p. 115). We hope that the materials of this special issue will be helpful for a wide circle of scientists interested in the problems of organic electrosynthesis.

V.P. Gul'tyai, A.G. Krivenko, and V.A. Petrosyan 